Provided for non-commercial research and education use. Not for reproduction, distribution or commercial use.

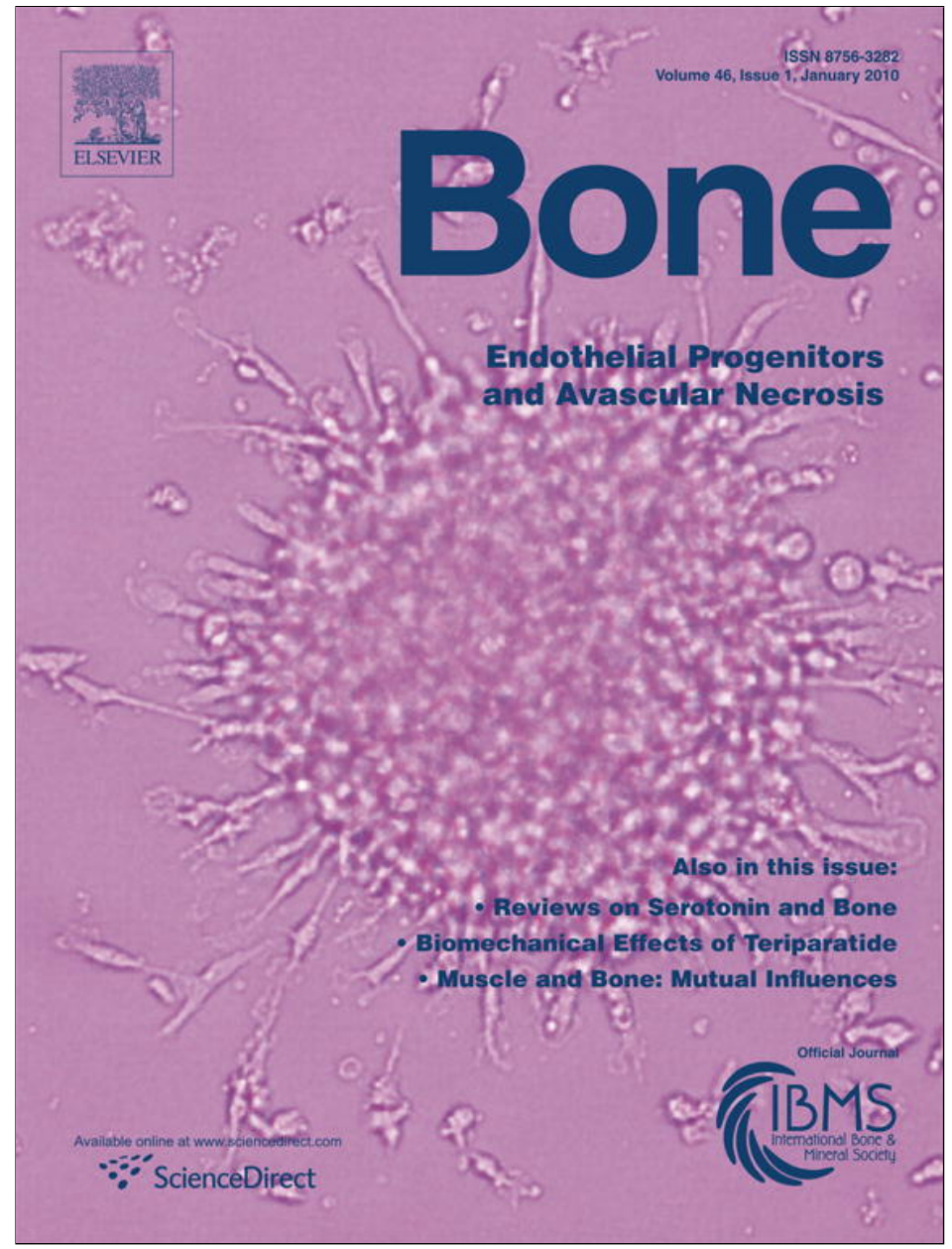

This article appeared in a journal published by Elsevier. The attached copy is furnished to the author for internal non-commercial research and education use, including for instruction at the authors institution and sharing with colleagues.

Other uses, including reproduction and distribution, or selling or licensing copies, or posting to personal, institutional or third party websites are prohibited.

In most cases authors are permitted to post their version of the article (e.g. in Word or Tex form) to their personal website or institutional repository. Authors requiring further information regarding Elsevier's archiving and manuscript policies are encouraged to visit:

http://www.elsevier.com/copyright 


\title{
Prevention of bone loss during 56 days of strict bed rest by side-alternating resistive vibration exercise
}

\author{
Jörn Rittweger ${ }^{\mathrm{a}, *}$, Gisela Beller ${ }^{\mathrm{b}}$, Gabriele Armbrecht ${ }^{\mathrm{b}}$, Edwin Mulder ${ }^{\mathrm{c}}$, Björn Buehring ${ }^{\mathrm{b}}$, \\ Ulf Gast ${ }^{\mathrm{b}}$, Fernando Dimeo ${ }^{\mathrm{d}}$, Harald Schubert ${ }^{\mathrm{e}}$, Arnold de Haan ${ }^{\mathrm{a}, \mathrm{c}}$, Dick F. Stegeman ${ }^{\mathrm{c}, \mathrm{f}}$, \\ Hans Schiessl ${ }^{\mathrm{e}}$, Dieter Felsenberg ${ }^{\mathrm{b}}$ \\ a Institute for Biomedical Research into Human Movement and Health, Manchester Metropolitan University, Manchester, UK \\ ${ }^{b}$ Center for Muscle and Bone Research, Charité-University Medicine, Free and Humboldt University Berlin, Berlin, Germany \\ c Research Institute MOVE, Faculty of Human Movement Sciences, VU University, Amsterdam, The Netherlands \\ d Section Sports Medicine, Charité-University Medicine, Free and Humboldt University Berlin, Berlin, Germany \\ e Novotec Medical, Pforzheim, Germany \\ ${ }^{\mathrm{f}}$ Department of Clinical Neurophysiology, Radboud University Nijmegen Medical Center, The Netherlands
}

\section{A R T I C L E I N F O}

\section{Article history:}

Received 31 March 2009

Revised 21 August 2009

Accepted 23 August 2009

Available online 2 September 2009

Edited by: D. Burr

\section{Keywords:}

Space flight

Microgravity

Countermeasure

Volumetric bone mineral density

Training

\begin{abstract}
A B S T R A C T
Bed rest is a recognized model for muscle atrophy and bone loss in space flight and in clinical medicine. We hypothesized that whole body vibration in combination with resistive exercise (RVE) would be an effective countermeasure.

Twenty healthy male volunteers underwent horizontal bed rest for 56 days and were randomly assigned either to a group that performed RVE 11 times per week or to a group that underwent bed rest only (Ctrl). Bone mineral content (BMC) was assessed by peripheral quantitative computed tomography (pQCT) in the tibia and the radius and by dual x-ray absorptiometry (DXA) in the hip and lumbar spine at baseline and at regular intervals during bed rest and a 12-month follow-up.

RVE appeared to protect muscle size and function, and it also prevented bone loss ( $p$-values between $<0.001$ and 0.01). Bone losses were largest in the distal tibia epiphysis, where BMC declined from $421.8 \mathrm{mg} / \mathrm{mm}$ (SD 51.3 ) to $406.6 \mathrm{mg} / \mathrm{mm}$ (SD 52.7) in Ctrl, but only from $411.1 \mathrm{mg} / \mathrm{mm}$ (SD 56.6) to $409.6 \mathrm{mg} / \mathrm{mm}$ (SD 66.7) in RVE. Most of the BMC losses were recovered by 12-month follow-up. Analyses showed that the epiphyseal cortex, rather than spongiosa, depicted the most pronounced changes during bed rest and recovery.

These results suggest that the combined countermeasure applied in this study is effective to prevent bone losses from the tibia. This underlines the importance of mechanical usage for the maintenance of the human skeleton.
\end{abstract}

(c) 2009 Elsevier Inc. All rights reserved.

\section{Introduction}

Bone loss and osteoporosis are a major concern for health care. One factor causing bone loss is immobilization, as is documented, for

\footnotetext{
is Funding sources: The BBR study was funded by grant $14431 / 02 / \mathrm{NL} / \mathrm{SH} 2$ from the European Space Agency. It was furthermore supported by Charité - University Medicine Berlin (Campus Benjamin Franklin), DLR (German AeroSpace), Novotec Medical, MSD Sharp \& Dohme, Lilly Germany, Servier Germany, Hoffmann-LaRoche, Siemens, Novartis, and Seca.

* Corresponding author. IRM Research Institute, All Saints Campus, Manchester M1 5GD, UK. Fax: +44161245751.

E-mail addresses: j.rittweger@mmu.ac.uk, ritmus@btinternet.com (J. Rittweger), gise.beller@charite.de (G. Beller), gabi.armbrecht@charite.de (G. Armbrecht), E.Mulder@neuro.umcn.nl (E. Mulder), b.buehring@googlemail.com (B. Buehring), belavy@gmail.com (U. Gast), fernando.dimeo@charite.de (F. Dimeo),

h.schubert@novotecmedical.de (H. Schubert), A_de_haan@fbw.vu.nl (A. de Haan), D.Stegeman@neuro.umcn.nl (D.F. Stegeman), schiessl_mail@gmx.de (H. Schiessl), Dieter.Felsenberg@charite.de (D. Felsenberg).
}

example, in spinal cord injury [1,2], in stroke [3], and also during bed rest [4]. Besides its obvious implications for clinical medicine, experimental bed rest is also of interest as a ground based model for simulated microgravity in humans [5-8]. As such, it lends itself to explore the efficacy of potential countermeasures for the prevention of physical de-conditioning $[9,10]$.

While resistive exercise during bed rest has been shown to prevent bed rest-induced muscle atrophy [11-14], it seems to be more difficult to combat bed rest-induced bone loss in the same way $[15,16]$. The best results have so far been achieved in a study by Shackelford et al. [17], in which resistive exercise was able to maintain bone mass in the calcaneus and in the lumbar spine during 17 weeks of bed rest. However, there seemed to be still some bone loss at some regions of the hip (e.g., trochanter) and the leg. Thus, the exercise regimen adopted in that study was probably largely but not fully effective to preserve bone strength. Moreover, the above study used dual x-ray absorptiometry (DXA) as endpoint, which does not provide as detailed information regarding the bone geometrical changes induced 
by bed rest and/or the countermeasure as would be possible by peripheral quantitative computed tomography (pQCT) $[18,19]$.

Evidence suggests that bones adapt to mechanical forces [20,21]. Given that virtually all skeletal muscles work against short levers [22], the largest habitual forces will arise from muscle contractions, rather than from gravity per se [23]. Accordingly, the body mass is used by the leg muscles to generate mechanical resistance. In conclusion, it seems that a successful exercise countermeasure to preserve bone during bed rest should involve large muscle forces. Vibration exercise has recently received considerable attention, not least for its potential to prevent bone loss or even increase bone mass and strength $[24,25]$. We hypothesized that whole body vibration, in combination with resistive exercise, would preserve muscle strength and prevent bone loss during bed rest. In order to test this hypothesis, we organized the Berlin BedRest (BBR) study in which young healthy male people were subjected to strict horizontal bed rest for 56 days. As a secondary hypothesis of this study we expected any losses incurring during the bed rest phase to be recovered within 1 year of follow-up.

Past studies have shown that bed rest-induced bone losses continue after reambulation [26-29]. Unfortunately, there are currently only few measurements available with long intervals in between them, which do not allow for an accurate assessment of this post-reambulation bone loss. We therefore decided to incorporate such measurements in the BBR study. In addition, recent studies of the bone losses induced by unilateral limb suspension and by experimental bed rest have shown that these losses occur predominantly from the cortical portion of the bone $[26,28]$. We were therefore specifically interested to see whether the proposed countermeasure would preserve the cortical portion of the distal tibia epiphysis.

\section{Materials and methods}

\section{Study design}

The BBR study was designed as a randomized controlled trial. It received approval from the Ethics Committee of the Charite-Campus Benjamin Franklin and is therefore compliant with the Declaration of Helsinki. The modalities of the study have been published elsewhere [30,31]. In brief, 20 young healthy male participants aged 20 to 45 , devoid of any musculoskeletal, mental, or blood clotting disorder, were recruited and randomly assigned to a group that either performed progressive resistive vibration exercise (RVE) or served as control participants (Ctrl). Both groups underwent 8 weeks of strict horizontal bed rest, with 3 days of baseline data collection before, and 14 days of post-reambulation data collection after the bed rest. During this entire period, diet was controlled using the Harris-Benedict [32] equation with an adjustment factor of 1.2 for bed rest [30]. Compliance with the protocol was ascertained by video cameras. No heparin was administered. Fourteen days after reambulation, participants were discharged from the hospital, but were followed up at regular intervals for 1 year.

The duration of the bed rest phase was set to 56 days, based upon our data from the long-term bed rest (LTBR) study [16]. In that study, bone losses after 56 days of bed rest predicted the losses after 90 days very well, with an $R^{2}$ value of 0.98 . Statistical power considerations were made under the assumption that $\alpha=0.05$ and $1-\beta=0.8$ and with the hypothesis that resistive exercise with vibration would be fully effective to counteract bone loss from the distal tibia epiphysis (= primary outcome). Assuming an average loss of $1.4 \%$ after 56 days of bed rest in the control group (SD 1.8\%) as found in the LTBR study [16], and expecting $S D=0.4 \%$ for the intervention group (as an upper limit for repeated pQCT measurements of tibial epiphyseal bone mineral content in our lab), a sample size of 10 per group was found to be sufficient in order to address our main hypothesis.
Table 1

Baseline characteristics of participants.

\begin{tabular}{lcc}
\hline & Ctrl & RVE \\
\hline Age [years] & $33.4(6.6)$ & $32.6(4.8)$ \\
Height $[\mathrm{m}]$ & $185(7)$ & $183(9)$ \\
Weight $[\mathrm{kg}]$ & $79.4(9.7)$ & $81.7(14.4)$ \\
Body mass index $\left[\mathrm{kg} / \mathrm{m}^{2}\right]$ & $23.3(1.7)$ & $24.2(1.6)$ \\
Trabecular BMD radius epiphysis $\left[\mathrm{mg} / \mathrm{cm}^{3}\right]$ & $239.3(28.1)$ & $229.9(26.7)$ \\
Trabecular BMD tibia epiphysis $\left[\mathrm{mg} / \mathrm{cm}^{3}\right]$ & $257.6(34.8)$ & $253.9(43.2)$ \\
Calf muscle cross section $\left[\mathrm{cm}^{2}\right]$ & $89.1(9.1)$ & $93.2(8.0)$ \\
Forearm muscle cross section $\left[\mathrm{cm}^{2}\right]$ & $48.4(3.7)$ & $47.9(5.6)$ \\
aBMD total hip $\left[\mathrm{g} / \mathrm{cm}^{2}\right]$ & $1.10(0.12)$ & $1.10(0.12)$ \\
t-score total hip $[\mathrm{SD}]$ & $0.46(0.78)$ & $0.43(0.80)$ \\
aBMD lumbar spine $(\mathrm{L} 1-\mathrm{L} 4)\left[\mathrm{g} / \mathrm{cm}^{2}\right]$ & $1.08(0.14)$ & $1.07(011)$ \\
t-score lumbar spine $(\mathrm{L} 1-\mathrm{L} 4)[\mathrm{SD}]$ & $-0.46(0.69)$ & $-0.24(1.04)$ \\
\hline
\end{tabular}

Values are given as means and their SD (in brackets). $n=10$. Data for the calf, forearm, and hip from both sides were taken.

\section{Participants}

Twenty participants were recruited who matched the inclusion criteria. All 20 participants completed the bed rest phase of the study, but 1 participant from the Ctrl group missed the 6-month and 1-year follow-up visits, and 1 participant from the RVE group missed the 3month and 1-year follow-up visits. Participant characteristics at baseline are given in Table 1, including anthropometric and osteodensitometric measures at baseline. None of these measures yielded a group difference.

\section{Training}

The RVE group exercised twice daily, except for Wednesday afternoons and Sundays, which were free of training. RVE was performed on a device that applies vibration in a side-alternating way, i.e., whilst the left leg is shortening, the right leg is lengthening, and vice versa. This side-alternating way of vibration leads to greater shock absorption in the legs than side-synchronous application [33] and is therefore usually better tolerated. The device has been specifically developed for this study (Galileo Space, Novotec Medical, Pforzheim, Germany), and its details have been described elsewhere $[30,31]$. It consists of a platform that is suspended from a trolley to which participants attach themselves in supine position by means of shoulder, hip, and hand belts (see Fig. 1). Elastic springs generate a

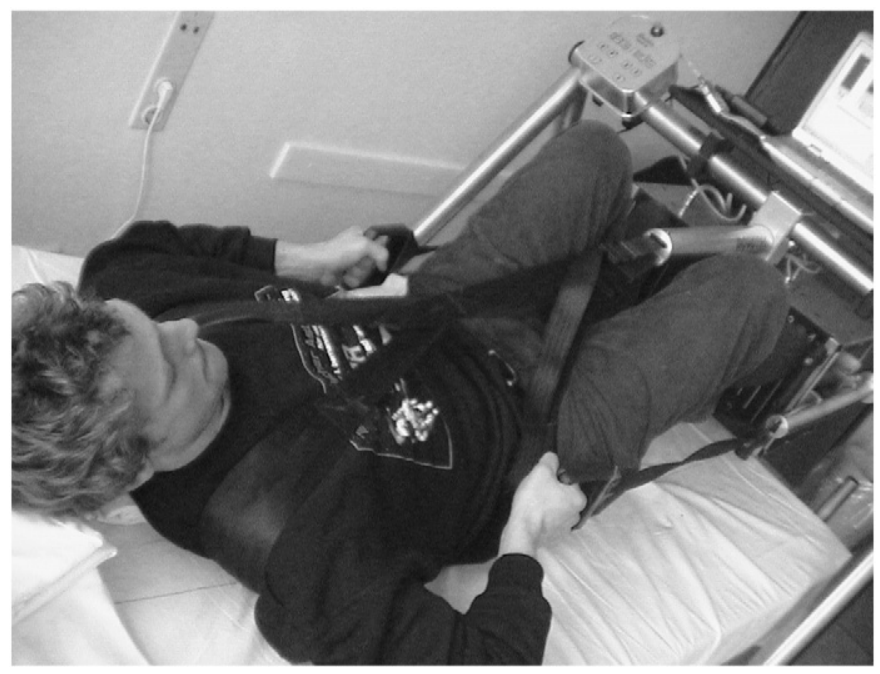

Fig. 1. Illustration of the Galileo Space training device (Novotec Medical, Pforzheim, Germany) used in this study. The device consists of a teetering platform suspended from a trolley, to which the participant is attached via belts and elastic springs in order to replace Earth's gravity. Platform vibration is generated by eccentric rotation of masses. 
resting force that imitates static gravitational acceleration, on top of which an oscillating force is added by means of eccentric mass rotation under the teetering foot-board. Notably, the oscillating forces increase with up to the square of the vibration frequency [30], and vibration frequency was thus used as the main parameter of exercise progression during this study.

During each training session, four different types of dynamic exercise were carried out, namely (a) squatting exercise, targeting the thigh muscles, (b) heel raises, targeting the calf muscles, (c) toe raises, targeting the shin muscles, and (d) 10 kicks, i.e., explosive squats with $10-$ $s$ rest insertion. The latter exercise was included into the training protocol based on the rationale that animal studies suggest that even submaximal osteogenic mechanical stimuli can elicit maximal bone responses if combined with 10-s rest insertion [34]. Exercises (a) to (c) were performed rhythmically at a repetition rate of 1 in 6 s. During morning sessions, the resting force was set to twice the body weight by adjustment of elastic springs. Exercise progression was by increase in vibration frequency, starting at $19 \mathrm{~Hz}$ and ending at up to $30 \mathrm{~Hz}$, depending on the individual capability. Vibration frequency was increased in steps of $1 \mathrm{~Hz}$ as and when participants tolerated the exercise for more than $100 \mathrm{~s}$, thus controlling exercise progression. During morning sessions, participants went through exercises (a) to (d) once, with up to $5 \mathrm{~min}$ for recovery between each of the exercises. In the afternoon sessions, the resting force was set to 1.4 times body weight, and subjects went through exercises (a) to (d) continuously until exhaustion, which was achieved within 5 to 10 minutes. All exercise sessions were supervised. This regimen was demanding and occasionally caused leg pain during the bed rest phase, but was overall well tolerated [30].

\section{Measurements}

Bone measurements were obtained once during baseline data collection (BDC), on days 2, 17, 31, 45, and 55 of the bed rest phase
(BR.2, BR.17, BR.31, BR.45, and BR.55, respectively), and 4, 14, 28, 90, 180 , and 360 days after reambulation $(R+4, R+14, R+28, R+90$, $R+180$, and $R+360$, respectively).

We obtained the pQCT scans from both arms and legs with an XCT2000 (Stratec Medizintechnik, Pforzheim, Germany) as described before $[16,35]$. In brief, scout-views were generated in the frontal plane to identify the distal tibia's joint surface to position the reference line. Next, sectional images were obtained from the tibia at $4 \%$ (distal epiphysis), $14 \%$ (metaphysis), 38\%, and 66\% (diaphysis) of its length. Table 2 gives an overview of the anatomical characteristics of the tibia at these sites. In the same way, sectional images were obtained from radius at $4 \%$ and $60 \%$ of the ulna's length. The scans taken at $66 \%$ of the tibia length and at $60 \%$ of the ulna length were also used for the assessment of the gross anatomical muscle cross sectional area (CSA). On the occasion of each pQCT scan, hand grip strength was measured at both hands using a TKK 5101 grip strength dynamometer (Takei Ltd., Tokyo, Japan).

Bone mineral content (BMC in g) of the lumbar spine (L1-L4 in anteroposterior projection) and the proximal femur (total and subregions in both sides) were measured using dual x-ray absorptiometry (DXA) with a Delphi W scanner (Hologic, Waltham, MA). Measurement and analysis (software version 11.2:7) were performed according to the manufacturer's standard protocol. DXA measurements were not undertaken on day $\mathrm{R}+14$.

All measurements were taken in horizontal position, and participants did not stand on their feet at any time of the bed rest phase.

\section{Data processing and statistical analysis}

The pQCT images were analyzed with the integrated XCT 2000 software (version $5.50 \mathrm{D}$ ), using the 'loop facility' to produce spreadsheets with the endpoint data, which were then further processed with Microsoft Access (2002). The total bone mineral

Table 2

Overview of the measurement sites in the tibia.

\begin{tabular}{|c|c|c|c|c|}
\hline & Epiphysis (4\%) & Metaphysis (14\%) & Diaphysis (38\%) & Diaphysis (66\%) \\
\hline \multicolumn{5}{|l|}{ Images from participant B } \\
\hline \multirow[t]{2}{*}{ Total BMC [mg/mm] } & Ctrl: 405.5 (49.9) & Ctrl: $311.9(27.5)$ & Ctrl: 432.3 (29.7) & Ctrl: $481.9(37.1)$ \\
\hline & RVE: 421.9 (61.7) & RVE: 306.4 (29.3) & RVE: 430.3 (33.7) & RVE: 478.0 (58.9) \\
\hline \multirow[t]{2}{*}{ Cortical area $\left[\mathrm{mm}^{2}\right]$} & Ctrl: $164.0(42.5)$ & Ctrl: 210.7 (24.6) & Ctrl: 346.7 (32.8) & Ctrl: 378.4 (39.5) \\
\hline & RVE: 160.1 (28.4) & RVE: 206.8 (19.7) & RVE: 348.9 (28.6) & RVE: 379.9 (50.3) \\
\hline \multirow[t]{2}{*}{ Cortical BMC [mg/mm] } & Ctrl: $107.2(22.3)$ & Ctrl: $236.0(27.4)$ & Ctrl: $396.0(40.4)$ & Ctrl: 417.7 (47.1) \\
\hline & RVE: 117.9 (29.1) & RVE: $231.6(23.3)$ & RVE: 399.3 (32.6) & RVE: 420.7 (55.9) \\
\hline \multirow[t]{2}{*}{ Cortical density $\left[\mathrm{mg} / \mathrm{cm}^{3}\right]$} & - & Ctrl: $1247.6(24.3)$ & Ctrl: 1210.3 (16.3) & Ctrl: 1185.8 (16.6) \\
\hline & & RVE: 1247.5 (19.1) & RVE: 1208.5 (15.5) & RVE: 1186.5 (18.0) \\
\hline Trabecular (and marrow) & Ctrl: $1150.9(163.3)$ & Ctrl: 327.6 (51.9) & Ctrl: $167.4(37.2)$ & Ctrl: 348.3 (59.9) \\
\hline Area area $\left[\mathrm{mm}^{2}\right]$ & RVE: 1134.7 (176.7) & RVE: $326.1(68.3)$ & RVE: $132.8(34.3)^{\mathrm{a}}$ & RVE: $306.4(46.7)^{\mathrm{b}}$ \\
\hline Trabecular (and marrow) & Ctrl: 298.3 (47.8) & Ctrl: $75.8(9.6)$ & Ctrl: $36.3(12.2)$ & Ctrl: $64.2(14.8)$ \\
\hline $\mathrm{BMC}[\mathrm{mg} / \mathrm{mm}]$ & RVE: 304.0 (41.4) & RVE: $74.9(14.1)$ & RVE: $31.0(5.9)$ & RVE: $57.3(10.1)$ \\
\hline \multirow[t]{2}{*}{$\mathrm{RPol}\left[\mathrm{cm}^{3}\right]$} & - & Ctrl: $1.71(0.21)$ & Ctrl: $2.17(0.22)$ & Ctrl: $3.11(0.35)$ \\
\hline & & RVE: $2.09(0.79)$ & RVE: $2.03(0.31)^{b}$ & RVE: $3.01(0.46)$ \\
\hline
\end{tabular}

Measurements were taken at $4 \%, 14 \%, 38 \%$, and $66 \%$ of the tibia's length from its distal end. As can be seen, the total bone mineral content (BMC) and polar moment of resistance (RPol) are smallest at the metaphyseal site and largest in the diaphysis. Whilst the epiphysis is mainly composed of trabecular bone (approximately $75 \%$ ), the diaphysis is composed almost exclusively of cortical bone. $n=10$ participants, with data being from both sides.

a Significant group differences at baseline with $p<0.01$.

b Significant group differences at baseline with $p<0.05$. 
content (BMC) of the tibia and the radius was determined using detection thresholds of $180 \mathrm{mg} / \mathrm{cm}^{3}$ for the epiphysis and of $710 \mathrm{mg} /$ $\mathrm{cm}^{3}$ for metaphysis and diaphysis. In order to attribute bone losses to either the cortical or the trabecular compartment, the cortical BMC was assessed with a threshold of $710 \mathrm{mg} / \mathrm{cm}^{3}$ at the diphyseal and metaphyseal sites and $480 \mathrm{mg} / \mathrm{cm}^{3}$ at the epiphysis. This way, all pixels within the detected bone contour and with an above-threshold density were assessed as cortical bone. The combined trabecular and marrow BMC was then computed as follows:

trabecular BMC $=$ total BMC - cortical BMC

Cortical BMD (crtBMD) values were assessed with adjustment for the partial volume effect as previously described [36]. For the diaphyseal sites, the polar moment of resistance (RPol) after adjustment of an 'ideal' cortical BMD of $1200 \mathrm{mg} / \mathrm{cm}^{3}$ was assessed as the 'RP_CM_W' value from the 'loop' database (this variable is also referred to as the 'strength strain index' or SSI by some authors). Calf and forearm muscle CSA were assessed by the automatic algorithm included in the XCT software package according to the manufacturer's recommendations, applying a detection threshold of $45 \mathrm{mg} / \mathrm{cm}^{3}$.

Missing data (for missed visits on day $\mathrm{R}+90, n=1$ ) were reconstructed by linear interpolation from adjacent available data points. Two participants could not be tested on day $R+360$, and those data sets were treated as missing data. None of the non-attendances were for reasons related to the study. As expected, there was no significant change in the bone measurements obtained on days BDC and BR.2 $(p>0.8)$. Hence, these data were used to assess the shortterm error $\operatorname{Err}_{\mathrm{ST}}$, in percent, as follows:

$\operatorname{Err}_{\mathrm{ST}}=\frac{100}{N} \cdot \sum \frac{\left|\bar{x}_{\mathrm{P}, \mathrm{BDC}}-x_{\mathrm{P}, \mathrm{BDC}-7}\right|}{\bar{x}_{\mathrm{P}, \mathrm{BDC}}}$

where $\bar{X}_{\mathrm{P}, \mathrm{BDC}}$ is the mean value of variable $x$ for participant $\mathrm{P}$ in both baseline measurements, $X_{P, B D C-7}$ is the value for participant $\mathrm{P}$ on day BDC-7, and $N$ is the total number of participants. $\operatorname{Err}_{\mathrm{ST}}$ is an approximation of the root-mean-square coefficient of variation $\left(\mathrm{CV}_{\mathrm{RMS}}\right)$, which cannot be computed here because only two baseline measurements are available per participant. The results for $\operatorname{Err}_{\mathrm{ST}}$ are given in Table 3.

One of the aims of the BBR study was to assess the time course of neuromuscular adaptations to bed rest. To this purpose, knee extensor function of the right leg was repeatedly re-assessed with a neuromuscular test battery during the bed rest phase on days 4,7 , $10,17,24,38$, and 56 [37]. As the left leg underwent no functional testing during this time frame, we felt that it was necessary to consider side differences (i.e., right vs. left leg) in the statistical analyses of the primary outcome for this study. Hence, group

Table 3

Short-term error.

\begin{tabular}{lllll}
\hline & Site & Total BMC & Cortical BMC & Trabecular BMC \\
\hline \multirow{2}{*}{ pQCT } & Tibia epiphysis (4\%) & $0.29 \%$ & $1.22 \%$ & $0.63 \%$ \\
& Tibia metaphysis (14\%) & $0.18 \%$ & $0.34 \%$ & $1.02 \%$ \\
& Tibia diaphysis (38\%) & $0.19 \%$ & $0.23 \%$ & $1.83 \%$ \\
& Tibia diaphysis (66\%) & $0.17 \%$ & $0.23 \%$ & $1.60 \%$ \\
& Radius epiphysis (4\%) & $0.45 \%$ & $4.43 \%$ & $2.41 \%$ \\
& Radius diaphysis (60\%) & $0.51 \%$ & $0.60 \%$ & $3.05 \%$ \\
DXA & Total hip & $0.86 \%$ & - & - \\
& Lumbar spine (L1-L4) & $1.01 \%$ & - & - \\
\hline
\end{tabular}

The short-term error, $\operatorname{Err}_{\mathrm{ST}}$, was computed for the bone parameters as given in Eq. (2) and is similar to the coefficient of variation. $n=10$. Data are from both sides. Generally, total BMC measurements at the tibia by PQCT yielded very good reproducibility that was in the same order of magnitude as repeated measurements of the standard phantom for the XCT [28]. Reproducibility was considerably poorer for DXA measurements, and also for the segregation of cortical and trabecular portions from the pQCT images. differences were assessed between baseline and $\mathrm{R}+14$, applying a repeated measures ANOVA model, using 'time' and 'side' (left vs. right) as within-subjects factor. BDC-values and 'group' were entered as covariates. Significant effects were followed up by simple contrasts. Efficacy of the countermeasure to prevent muscle atrophy and bone loss was assessed with a paired-samples $t$-test.

The time course of the post-reambulation bone loss was assessed from the five BMC values obtained between days BR.55 and R+90. For each individual, values were normalized by the maximal bone loss (as the difference in BMC from baseline) observed within this period. For this analysis, only a subgroup of data sets from the Ctrl group was included, namely those with substantial losses, exceeding $2 \mathrm{mg} / \mathrm{mm}$ for the epiphyseal, metaphyseal, and 38\% diaphyseal sites and $3 \mathrm{mg} /$ $\mathrm{mm}$ for the $66 \%$ diaphyseal site. These cut-off values correspond to the values for the least effective change for in-vivo measurements by pQCT in our hands [16,35]. Out of the 20 datasets (one for either side in each of the 10 control participants), 20,12,14, and 14 datasets were used for the $4 \%, 14 \%, 38 \%$, and $66 \%$ tibia sites, respectively. The completeness of recovery at the end of the 1-year follow-up was tested with a paired-samples $t$-test.

In order to assess the temporal relationship between changes in muscle cross section and in bone mineral content, cross-correlation analysis was applied. To that end, all data were re-sampled by linear interpolation between BR. 3 and $R+168$, so as to obtain data sampled at regular intervals of 14 days. Pearson's correlation coefficients were assessed with varying positive and negative time lags between both time series for each individual, which were then averaged across people per group and time lag.

Significance levels were adjusted for multiple comparisons by Bonferroni's method. For all statistical tests, significance was assumed for $p<0.05$. Statistical analyses were performed with SPSS for Mac (version 11.0.4 of 18 Aug 2005).

\section{Results}

\section{Muscle changes}

For calf muscle CSA, significant interactions between time and CSA at baseline were found $(p=0.003)$, suggesting that muscle losses were in proportion to muscle size at baseline. Moreover, a time* group interaction was found ( $p<0.001$, see Fig. 2 ), suggesting changes over time were different between groups. Calf muscle CSA was significantly reduced at the end of bed rest $(p<0.001$, see Table 4$)$. Despite a significant group difference, there was still a significant reduction in calf muscle CSA in the RVE group $(p<0.001$, see Table 4$)$. No side effect (right/left) was found $(p>0.2)$, indicating that the neuromuscular test battery had no effect upon calf muscle CSA. Intriguingly, the reduction in calf muscle CSA was reverted into a small but significant gain after 12-month recovery in the Ctrl group $(p=0.004)$, but not in the RVE group.

Data on leg muscle function have been published elsewhere. In brief, whilst the Ctrl group lost approximately $20 \%$ of their isometric knee extension and plantar flexion strength, there was no such loss observed in the RVE group $[37,38]$. In agreement with the changes observed in calf muscle size reported here, knee extensor CSA also declined for both groups, namely from $82.5 \mathrm{~cm}^{2}$ (SD $5.9 \mathrm{~cm}^{2}$ ) to $71.7 \mathrm{~cm}^{2}$ (SD $6.4 \mathrm{~cm}^{2}$ ) for Ctrl and from $86.0 \mathrm{~cm}^{2}\left(\mathrm{SD} 8.1 \mathrm{~cm}^{2}\right)$ to $81.5 \mathrm{~cm}^{2}$ (SD $7.2 \mathrm{~cm}^{2}$ ) for RVE [37].

Whereas no changes in knee extensor strength emerged during the 12-moth follow-up in the RVE group, recovery in the Ctrl participants was achieved somewhere between 14 and 28 days after reambulation. Interestingly, a tendency towards enhanced muscle strength $(\sim 7 \%)$ was observed from $\mathrm{R}+90$ onward ( $t$-test $p$-values were $0.058,0.093$, and 0.073 for $R+90, R+180$, and $R+360$, respectively). No such observations were, however, seen in the RVE group. 

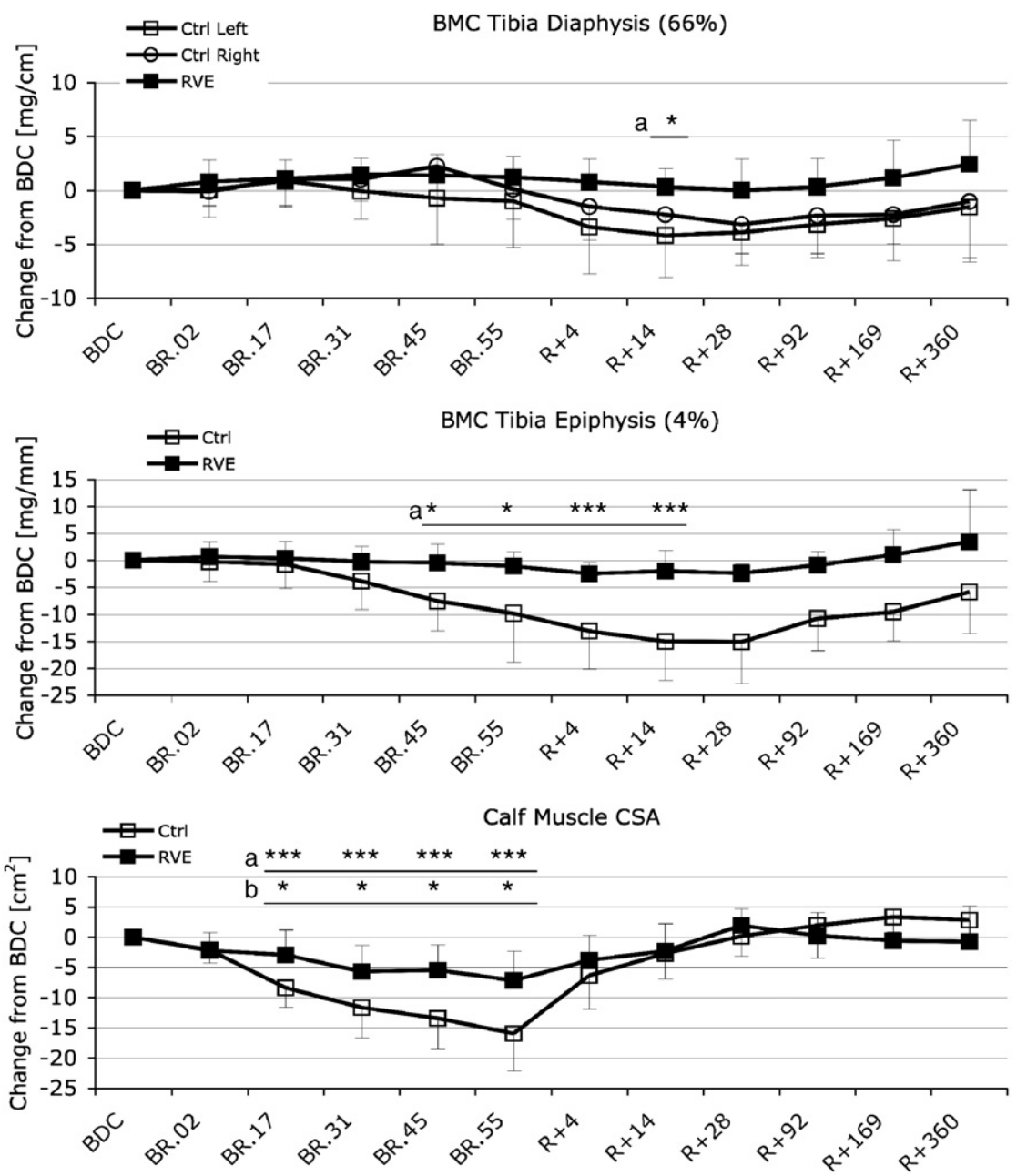

Fig. 2. Calf muscle cross sectional area and bone mineral content of the distal tibia epiphysis (4\%) and at the tibia diaphysis (66\%) throughout the study. Values are given as the difference from baseline and their SD. Visual inspection revealed potential differences between the right and left tibia diaphysis in Ctrl. Therefore, these values are given separately. All other data are means from both legs. When comparing the responses to bed rest and also to reambulation, it can be appreciated that BMC changes are delayed and slower than calf muscle CSA changes (see also Fig. 5). (a) Significant time* group interaction. (b) Significant interaction between value at baseline with time. Differences from baseline: *, $<<0.05$; **, $p<0.01 ; * * *, p<0.001$.

\section{Tibia changes}

\section{Total bone mineral content}

Except for the $38 \%$ diaphysis, significant group*time interaction effects were found in all tibia sites, with $p$-values ranging between $<0.001$ (epiphysis and metaphysis) and 0.01 (66\% diaphysis, see Fig. 2). Importantly, there was no interaction observed between baseline values and time ( $p>0.30$ in all cases), implying that bone losses were independent of the initial bone mineral content at baseline.

Table 4

Gross muscle cross sectional areas, as assessed by pQCT.

\begin{tabular}{lllll}
\hline Muscle CSA $\left[\mathrm{cm}^{2}\right]$ & & BDC & BR.55 & R+360 \\
\hline Calf & Ctrl & $90.1(10.3)$ & $73.9(7.7) p<0.001$ & $92.9(9.6) p=0.004$ \\
& RVE & $95.8(5.8)$ & $88.1(7.1) p<0.001$ & $95.4(8.3) p=0.74$ \\
Forearm & Ctrl & $47.8(3.6)$ & $47.3(3.2) p=0.27$ & $48.4(3.4) p=0.56$ \\
& RVE & $48.0(6.0)$ & $47.7(6.0) p=0.81$ & $47.9(5.9) p=0.85$ \\
$n$ & Ctrl & 10 & 10 & 9 \\
& RVE & 10 & 10 & 9 \\
\hline
\end{tabular}

Values for the calf (at $66 \%$ of the tibia length from its distal end) and for the forearm (at $60 \%$ of the ulna length from the distal radius end) muscle cross sectional area (CSA) are given as means and their SD (in brackets). Data from both sides were taken for analysis. $n$ is the number of participants. $P$-values denote significance of changes from baseline data collection (BDC). In both groups, there was a significant loss in calf muscle CSA at the end of bed rest (BR.55), which was reversed to a small but significant gain in the control (Ctrl) group on day $\mathrm{R}+360$, but not in the exercise group (RVE).
Losses were significant on day $\mathrm{R}+14$ at all measured sites in the Ctrl group ( $p=0.008$ for the $38 \%$ diaphyseal site and $p<0.001$ for all other sites, see Table 5), and they were largest in the epiphysis where they amounted to $-2.3 \%$ (SD 2.3\%) on day BR.55 and $-3.6 \%$ (SD 1.9\%) on day $\mathrm{R}+14$ in the Ctrl group. By contrast, no significant change was observed in the RVE group, although it should be noticed that the small reduction observed at the tibia epiphysis yielded a $p$-value of 0.06 and hence just failed to reach statistical significance.

At 12-month follow-up losses were still significant in the Ctrl group at the distal tibia epiphysis $(p=0.002)$, but not at any other site $(p>0.2)$, implying full recovery for the metaphyseal and diaphyseal sites, but not for the epiphysis. Quite surprisingly, there were small gains in BMC observed in the RVE group at the 38\% and 66\% diaphyseal sites at this time ( $p=0.034$ and $p=0.046$, respectively, see Table 5).

No change was found in RPol throughout the study.

Post-reambulation bone loss (total BMC)

Fig. 3 shows the time course of bone loss in the Ctrl group during early recovery from days BR.55 to $R+90$. Essentially, the time course of this post-reambulation bone loss was similar in all sites and individuals studied, with bone mass starting to recover only after a trough somewhere between 14 and 28 days after reambulation. Apparently, post-reambulation bone losses were relatively more pronounced in the diaphyseal regions, where they amounted to approximately $80 \%$ of the overall loss. 
Table 5

Bone mineral content, assessed by pQCT.

\begin{tabular}{|c|c|c|c|c|}
\hline Total BMC $[\mathrm{mg} / \mathrm{mm}]$ & & $\mathrm{BDC}$ & $\mathrm{R}+14$ & $R+360$ \\
\hline \multirow[t]{2}{*}{ Tibia epiphysis(4\%) } & Ctrl & $421.8(51.3)$ & $406.6(52.7) p<0.001$ & $415.8(54.1) p=0.002$ \\
\hline & RVE & $411.1(65.6)$ & $409.6(66.7) p=0.06$ & $414.5(66.7) p=0.31$ \\
\hline \multirow[t]{2}{*}{ Tibia metaphysis (14\%) } & Ctrl & $309.3(28.9)$ & $306.6(27.2) p<0.001$ & 308.7 (29.7) $p=0.49$ \\
\hline & RVE & $306.9(31.1)$ & $306.6(31.6) p=0.38$ & $309.7(29.7) p=0.24$ \\
\hline \multirow[t]{2}{*}{ Tibia diaphysis (38\%) } & Ctrl & $429.4(30.2)$ & $426.8(28.9) p=0.008$ & 430.9 (32.7) $p=0.29$ \\
\hline & RVE & $430.8(35.6)$ & $430.6(36.5) p=0.63$ & $434(34.8) p=0.034$ \\
\hline \multirow[t]{2}{*}{ Tibia diaphysis (66\%) } & Ctrl & $479.1(38.7)$ & 475.8 (36.9) $p<0.001$ & $477.8(40.1) p=0.58$ \\
\hline & RVE & $479.9(62.5)$ & $480.4(62.9) p=0.88$ & $482.3(61.7) p=0.046$ \\
\hline \multirow[t]{2}{*}{ Radius epiphysis (4\%) } & Ctrl & $160.4(15.9)$ & $160.3(15.7) p=1.0$ & $160.9(16.1) p=0.56$ \\
\hline & RVE & $160.9(33.8)$ & $160.9(33.6) p=0.81$ & $162.5(33.0) p=0.096$ \\
\hline \multirow[t]{2}{*}{ Radius diaphysis (60\%) } & Ctrl & $125.9(13.1)$ & $125.5(12.2) p=0.85$ & $125.3(12.6) p=0.52$ \\
\hline & RVE & $127.6(28.5)$ & $127.5(29.0) p=0.66$ & $127.7(29.0) p=0.61$ \\
\hline \multirow[t]{2}{*}{$n$} & Ctrl & 10 & 10 & 9 \\
\hline & RVE & 10 & 10 & 9 \\
\hline
\end{tabular}

BMC values at baseline (BDC), on the 14th day of recovery, and at 12-month follow-up ( +360$)$, given as means and their SD in brackets. Data are from both sides. $n$ is the number of participants. P-values denote significance of changes from baseline. Whilst significant losses occurred between BDC and R+14 in the tibia in the control group (Ctrl), no such change was found in the RVE group.

\section{Bone loss distribution}

When analyzing the distribution of bone losses within the tibia epiphysis, it appeared that both BMC and area remained unchanged in the RVE group (see Fig. 4). However, the Ctrl group depicted significant time effects for cortical and trabecular BMC $(p<0.001$ and $p=0.032$, respectively) as well as for cortical and trabecular area $(p<0.001$ and $p=0.035$, respectively). As can bee seen from Fig. 4 trabecular area increased and cortical area decreased in the Ctrl group from day BR.17 onwards, with both of these changes matching each other. Similarly, cortical BMC started to decline on day BR.17 in the Ctrl group, but there was very little or no change occurring in the trabecular BMC during the bed rest phase itself. However, when looking at the time course of trabecular BMC in the Ctrl group between days BR.55 and R+4, one can observe a one-time drop, with virtually no change before and after this time point. Hence, virtually all of the trabecular bone losses incurred seem to have occurred during theses very first days after reambulation. Interestingly, during 12 months of follow-up the cortical BMC losses were fully recovered in this group, whereas trabecular losses were not.

Changes in the diaphyseal and metaphyseal regions were less pronounced. There was no time* group effect in cortical area, and a significant $(p=0.004)$ but small $\left(<0.5 \mathrm{~mm}^{2}\right)$ effect for the combined trabecular and marrow area at the metaphysis, but not at the diaphysis. There were, however, significant time* group effects for cortical BMC and cortical BMD at the metaphysis and at the diaphysis

Tibia BMC after Re-Ambulation

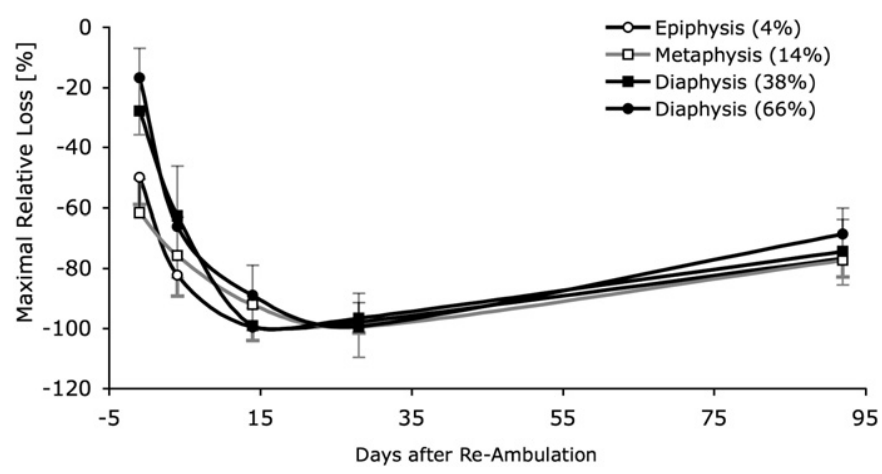

Fig. 3. Modeling bone losses that incurred after reambulation. Data from both sides have been lumped together. For each participant and tibia site, the largest loss from baseline was assumed to be $100 \%$. It appears that post-reambulation losses were particularly pronounced in the two diaphyseal sites. (except for cortical density at the metaphysis, where $p=0.07$ ). These effects are exemplified in Fig. 5 for the 66\% diaphyseal site. Apparently there was very little or no change in the RVE group. By contrast, cortical BMC in the Ctrl group tended to continuously decrease during the bed rest and until 4 weeks thereafter, and to return to baseline values by 12-month follow-up. There tended to be an increase in cortical BMD during bed rest in both groups. By contrast, cortical BMD decreased markedly after reambulation by approximately $5 \mathrm{mg} / \mathrm{cm}^{3}$ in the Ctrl group, and this abrupt drop did not recover within the 12month follow-up. This lack in recovery of cortical BMD, however, was not significant and it seemed to be specific to the $66 \%$ diaphyseal sites (see Table 6).

\section{Temporal comparison of muscle and bone changes}

For all measurement sites, changes in calf muscle cross sectional area were preceding changes in tibia bone mineral content by approximately 14 days. This was the case both in the RVE as well as in the control group, as exemplified in Fig. 6.

\section{Hip and lumbar spine changes}

No significant time or time* group interaction was observed for lumbar spine BMC $(p>0.5)$. However, when carefully inspecting the percent changes over time in Fig. 6 , there seemed to be a very abrupt loss between BDC and the second day of bed rest by some $2 \%$ that was constantly maintained throughout the bed rest. Strikingly, all or most of this loss was readily recovered between day BR.55 and $\mathrm{R}+14$.

Likewise, no significant effects were found for total hip BMC. Visual inspection of the error bars on day BR.01 in Fig. 6, however, along with the Table 3, suggested that the lack of significance is due to considerable measurement variation. In the lower panel of Fig. 3, bone losses appear to be smaller for the RVE as compared to the Ctrl group, but also smaller for the right than for the left hip in either group. As a surprising finding, total hip BMC in the RVE group was elevated above baseline levels at 12-month follow-up (see Table 7).

\section{Forearm}

Neither were there any changes observed in forearm muscle CSA or grip strength throughout bed rest or the follow-up, nor was there any group effect. Similarly, we found no change in BMC of the distal radius epiphysis (see Table 5). ANOVA picked up a time effect $(p=0.011)$ for BMC at the $60 \%$ site of the radius, which, however, seemed to be specifically related to two unduly variant $\mathrm{R}+4$ measurements, and which was therefore not further considered. 
Tibia Epiphysis (4\%)
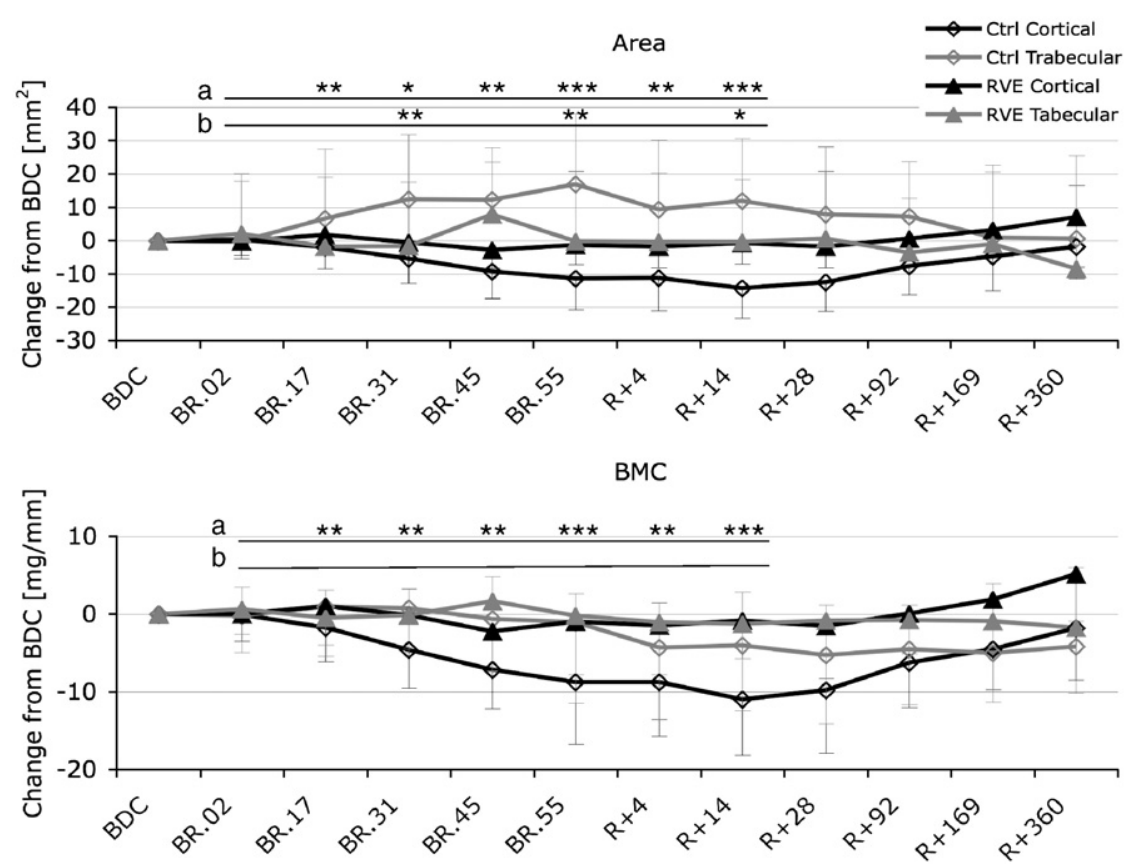

Fig. 4. Assessment of the distribution of bone losses in the cortical and trabecular portion of the tibia epiphysis. Values are given as the difference from baseline and their SD. Data are from both sides. It becomes clear from this figure that the overall epiphyseal bone loss depicted in the medium panel of Fig. 1 is largely due to a loss of cortical bone. No changes were observed in the exercise group (RVE). Significant time* group interaction for cortical (a) and trabecular (b) portions. Asterisks denote differences from baseline: *, $p<0.05$; $* *$, $p<0.01 ; * * *, p<0.001$

\section{Discussion}

The results of this study demonstrate that a combined training regimen, involving side-alternating whole body vibration, resistive elements, and explosive squats with rest insertion, is able to prevent bone losses from the tibia during 56 days of bed rest. There was still a decline in calf muscle cross section in the training group. However, this is unlikely to be due to true muscle atrophy, as calf muscle force generation appeared to be completely preserved in the training group [38]. Very likely, therefore, the observed loss in calf muscle cross section was an effect of anti-orthostatic fluid shifts [39]. Hence, our data suggest good efficacy of the combined countermeasure for muscle and bone.

The bone losses observed in the control group were highly significant, although comparatively small. When comparing them to results from the LTBR study [16], where the total BMC loss in the distal tibia epiphysis was 5.2\% (SD 4.5\%) after 89 days, it seemed that the loss by $2.3 \%$ (SD 2.3\%) after 55 days of bed was relative small. Several factors could account for that seeming difference across the two studies, such as the fact that the LTBR study was in $-6^{\circ}$ head down tilt, whereas the current study involved horizontal bed rest. However, it should be kept in mind that bone losses depict enormous interindividual differences [16], and that for example the small subgroup $(n=3)$ of the LTBR study used for our sample size estimation (see above) depicted a loss of only $1.4 \%$ on day BR.56. A final judgment of possible systematic differences between studies is therefore impossible.

In a previous study, Shackelford et al. [17] have reported prevention of bone loss by progressive resistive exercise, whereas calf muscle strength was actually increased by 50\% in the training group. Conversely, the flywheel training applied in the LTBR study failed to maintain calf muscle force $[13,40]$ and was ineffective to prevent bone losses $[15,16]$. Taken together, and in consideration of the observation that losses in calf muscle cross section were generally preceding changes in bone mineral content (Fig. 6), our results suggest that maintenance of muscle force is a prerequisite for the maintenance of bone mass in bed rest. In a broader sense, therefore, results from bed rest studies support the idea of musculature being an important determinant of bone strength [35,41-44]. These results constitute an important milestone on the way to develop effective countermeasures for long-term space missions. Moreover, they have implications for clinical medicine in that they show that physical interventions can, in principle, prevent bone losses and thus potentially help to mitigate the risk of fractures in cases of immobilization, such as stroke or spinal cord injury.

\section{Post-reambulation bone loss}

In addition to its principle result, this study has also provided new insights into the intricacies of immobilization-induced bone loss and its recovery. As previously observed after bed rest with $-6^{\circ}$ head down tilt [16], after horizontal bed rest [28], and after unilateral lower limb suspension [26], bone loss in the tibia continued after reambulation also in this study (see Figs. 2 and 3). As all of the former studies provided only one pQCT measurement within the first weeks of recovery, the time course of this post-reambulation bone loss was unknown. The data presented here show clearly that post-reambulation bone loss is a rather steady process, with the trough occurring approximately 20 days after reambulation in all sites investigated. Moreover, post-reambulation bone loss constituted a considerable portion of the overall bone loss, amounting to $80 \%$ for diaphyseal losses and to approximately $40 \%$ of epiphyseal and metaphyseal losses (Fig. 3 ) in this 56 days of bed rest study. It has to be considered that, whilst all 20 datasets could be used for the tibia epiphysis, the analysis in Fig. 3 is based on a subset of 12-14 datasets only for the metaphyseal and diaphyseal sites. Given that the time course was very similar among all participants tested, however, we are confident that the observed post-reambulatory bone loss with a trough around 20 days constitutes a general phenomenon.

The cause of this post-reambulation bone loss is unknown. First of all, according to the 'muscle-bone hypothesis' bones will adapt to forces generated by the musculature, and it has been suggested that 
Tibia Diaphysis $(66 \%)$
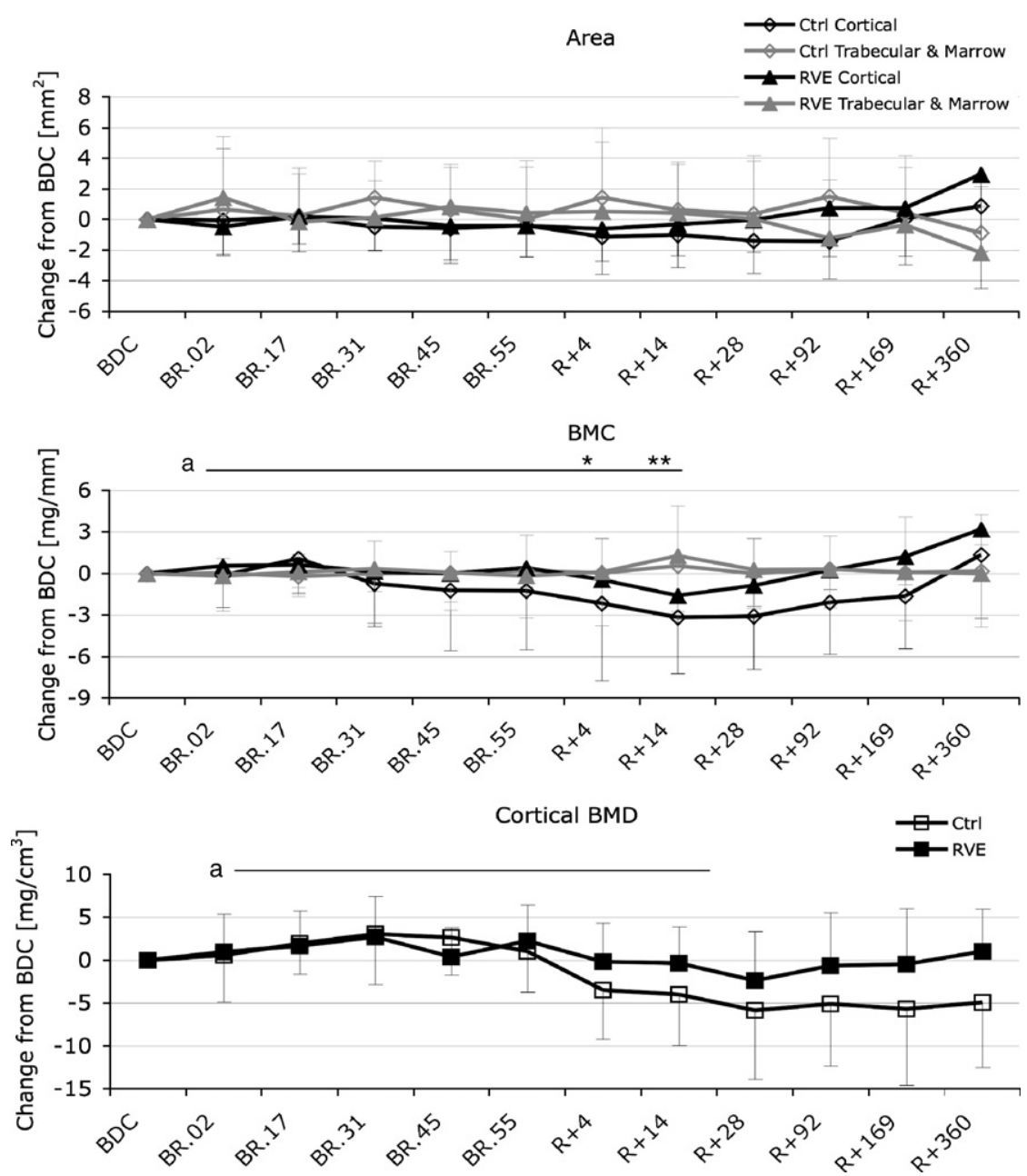

Fig. 5. Assessment of the bone loss distribution in the tibia diaphysis ( $66 \%$ site). Values are given as the difference from baseline and their SD. Data are from both sides. No change was observed in cortical or combined marrow and trabecular bone area in either group (upper panel). In the control (Ctrl) group, however, there appeared to be a loss in cortical bone mineral content (medium panel), which was accelerated after reambulation, mainly as a result of decreased cortical density. (A) Significant time* group interaction. Asterisks denote differences from baseline: *, $p<0.05 ; * *, p<0.01$.

'minimal effective strains' induce bone loss by remodeling or bone gain by modeling $[45,46]$. In this study, the time course of recovery between muscle and bone tissue diverges. As can be seen from the lower panel in Fig. 2, muscle atrophy in the Ctrl group (and also isometric force, not shown here) recovered largely within 14-28 days after reambulation. At this time, bone losses were still on-going or just stopping, making the 'muscle-bone' hypothesis a somewhat unlikely explanation for the observed phenomenon.
A second possible explanation considers transitional effects in bone adaptive processes. Bones are thought to continuously adapt to their mechanical requirements [47]. Hence, un-loading should lead to suboptimal mechanical properties, and re-loading must be expected to enhance the risk of bone microdamage [48]. The latter will cause targeted remodeling $[49,50]$ and thus temporary bone losses [46,51]. Bearing in mind the time that the homing of osteoclast precursors and the activation of osteclasts requires [52], one would expect a 'boost' of

Table 6

Cortical bone mineral density.

\begin{tabular}{|c|c|c|c|c|}
\hline $\operatorname{crtBMD}\left[\mathrm{mg} / \mathrm{cm}^{3}\right]$ & & $\mathrm{BDC}$ & $\mathrm{R}+14$ & $R+360$ \\
\hline \multirow[t]{2}{*}{ Tibia metaphysis (14\%) } & Ctrl & $1245.7(25.1)$ & $1241.6(26.9) p=0.008$ & $1243.3(26.3) p=0.22$ \\
\hline & RVE & 1246.7 (20.1) & $1245.8(20.4) p=0.31$ & $1245.5(21.0) p=0.32$ \\
\hline \multirow[t]{2}{*}{ Tibia diaphysis (38\%) } & Ctrl & $1207.4(16.5)$ & $1202.4(15.1) p=0.012$ & $1203.6(13.4) p=0.12$ \\
\hline & RVE & $1206.3(14.8)$ & $1207.8(16.0) p=0.29$ & $1207.6(13.1) p=0.39$ \\
\hline \multirow[t]{2}{*}{ Tibia diaphysis (66\%) } & Ctrl & $1183.8(16.1)$ & $1179.2(17.6) p=0.024$ & $1178.9(15.1) p=0.042$ \\
\hline & RVE & $1183.4(17.7)$ & $1183.6(15.4) p=0.75$ & $1184.4(15.4) p=0.35$ \\
\hline \multirow[t]{2}{*}{$n$} & Ctrl & 10 & 10 & 9 \\
\hline & RVE & 10 & 10 & 9 \\
\hline
\end{tabular}

Values are given at baseline (BDC), on the 14th day of recovery, and at 12-month follow-up (R+360) as means and their SD in brackets. Data are from both sides, and $n$ is the number of participants. $P$-values denote significance of changes from baseline. Whilst significant losses occurred between BDC and $R+14$ in the tibia in the control group (Ctrl), there was no such change found in the RVE group 3. 


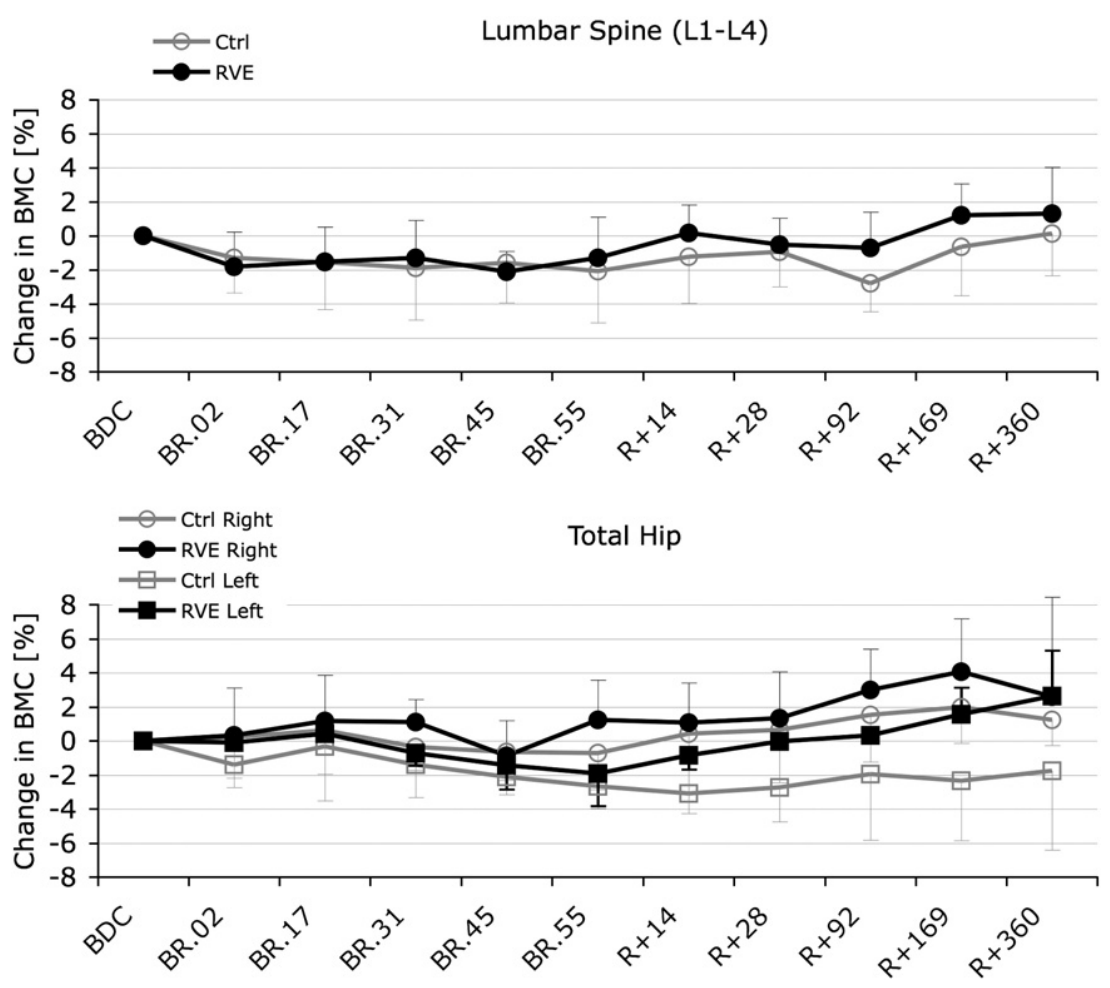

Fig. 6. Results from the DXA measurements of the hip and the lumbar spine. Changes in BMC are expressed as \% change from baseline. No significant effects were found by ANOVA. For further explanation see text.

bone resorption as a result of increased microdamage rate 1 or 2 weeks after reambulation. Our data may provide some evidence in support of this view. In the Ctrl group, for example, we found a onetime 'drop' in trabecular BMC (lower panel in Fig. 4) and in diaphyseal cortical density (lower panel in Fig. 5), albeit between days BR.55 and $\mathrm{R}+4$ and thus somewhat early. More convincingly, there was a significant increase in urinary desoxy-pyridinoline excretion (indicating bone resorption) between the 6th and 13th day after reambulation in the LTBR study [29]. On the other hand, such increased bone resorption following reambulation has not been observed in other bed rest studies [53,54], and also not in this study [31], although biochemical markers of bone metabolism have not been assessed between days $\mathrm{R}+7$ and $\mathrm{R}+28$ in this study, leaving open the possibility of a short boost of bone resorption due to increased microdamage formation early on during recovery from long-term bed rest.

\section{Distribution of bone loss}

Tibia epiphyseal bone losses in the Ctrl group were almost exclusively from the cortical portion (lower panel in Fig. 4). This is despite the fact that only a small part of the epiphysis is composed of cortical bone (approximately one fourth, see Table 2). Given that trabecular bone area increased by the same amount in the Ctrl group as cortical bone area decreased (upper panel in Fig. 4), it seems that epiphyseal losses were by endocortical resorption.

These findings are in line with recent studies on bone losses from the hip and spine during spaceflight [55] and on tibial bone losses induced by experimental bed rest [28]. The endocortical layer has been described as a transitional zone with high bone turnover [56], and indirect evidence suggests that this transitional zone responds most readily to un-loading [28]. It is perceivable that cortical thinning, which must result from the endocortical resorption, may increase the acute risk of fracture. In this context, it is worth mentioning that one of the participants of the Ctrl group attracted a bone burst when performing a jump test during early recovery. Moreover, evidence suggests that cortical thinning precedes osteoarthritis [57], alluding to a possible role of musculoskeletal un-loading and re-loading in the emergence of osteoarthritis.

Interestingly, there seemed to be virtually no bone loss from the trabecular compartment during bed rest at all. Again, this is in line with the recent study by Rittweger et al. [28], but it is in apparent contrast to the study by Lang et al. [55], who do report equally large losses from the trabecular and from the cortical compartment in the

Table 7

Bone mineral content, assessed by DXA.

\begin{tabular}{llll}
\hline BMC [mg] & & BDC & R+14 \\
\hline Total hip & Ctrl & $50.4(6.7)$ & $49.7(6.5) p=0.063$ \\
& RVE & $49.8(10.4)$ & $49.8(10.4) p=0.90$ \\
Lumbar spine (L1-L4) & Ctrl & $77.5(86)$ & $76.5(8.6) p=0.16$ \\
$n$ & RVE & $80.4(19.5)$ & $80.5(18.8) p=0.96$ \\
& Ctrl & 10 & 10 \\
& RVE & 10 & 10 \\
\hline
\end{tabular}

Measurements were taken at baseline (BDC), on the 14th day after reambulation ( $R+14)$, and at 12-month follow-up ( $R+360)$, given as means and their SD in brackets. Hip data stem from both sides. $n$ is the number of participants. $P$-values denote significance of changes from baseline. The only significant change was an increase in total hip BMC at $R+360$ in the RVE group. The reason for a lack of significant losses at R+14 may be a combination of smaller changes at the hip and spine as compared to the tibia, as well as a poorer reproducibility of the DXA measurements as compared to the pQCT technique (see Table 2). 
spine and in the hip. Although those authors applied a slightly different technique (spiral CT vs. pQCT), it is possible that these apparent differences are due to some anatomically specific mechanisms. Such potential mechanisms may well be involved in the emergence of osteoporosis, given that the trabecular portions of the spine and the hip are primary target sites of osteoporotic fractures.

Finally, bone losses in the diaphysis were comparatively small, although they were significant in the control group. No significant change was observed in cortical area or in the polar moment of resistance, suggesting that bone losses here were probably due to small increases in intra-cortical remodeling and endocortical resorption, which, however, both did not reach statistical significance on their own.

\section{Recovery}

Interestingly, there was an increase in calf muscle cross section by approximately $3 \%$ in the Ctrl group after 1 year (Table 4 ), but not in the RVE group, where values had just returned to baseline. Conversely, in the LTBR study, where training was insufficient to maintain calf muscle force in the training group, hypertrophy was observed in all groups, including the exercise intervention group, at 1year follow-up [29]. It seems therefore that some sort of 'superrecovery' is inherent to the rehabilitation of muscle atrophy.

As to the recovery of bone, our data suggest complete recovery at tibia diaphysis and metaphysis after 12-month follow-up, but not at the tibia epiphysis. It should be appreciated that epiphyseal bone losses were greater than those at the other tibial sites, and it therefore is possible that rehabilitation of the tibia epiphysis just takes longer time [29]. However, a look at the lower panel of Fig. 4 suggests that all of the epiphyseal recovery was limited to the cortical portion, and that there was no tendency of recovery within the trabecular portion throughout the 12-month follow-up. These results may indicate that cortical bone is more affected by mechanical usage than trabecular bone, in line with a report by Hagino et al. [58] that trabecular bone in rat is more susceptible to hormonal than to mechanical stimuli. It should be also considered here that trabecular BMC in this study started to decline only after reambulation. As alluded to above, acute microdamage might have caused this abrupt change, leading to a loss of trabeculi which is thought to be non-restorable.

Finally, there is some indication that diaphyseal bone strength in the training group was not only recovered, but even augmented after 1-year follow-up (Table 5). Inspection of the raw data suggests that this was a consistent finding within the training group, with gains in cortical BMC by up to $4.5 \%$ by the time of 12 -month follow-up. Moreover, this surplus seemed to be gained on the periosteal surface. Potentially, this phenomenon could be explained with the principle of cellular accommodation [59].

\section{Limitations}

When planning the study, we combined different exercise principles, hoping that in combination they would constitute an efficient countermeasure for preservation of muscle and bone. Because of this approach, we can identify neither the single contributions of vibration or resistance training nor the complementary effects of both training modes. However, this was not the scope of this study. Hence, whilst the present results show that, in principle exercise countermeasures are able to preserve muscle force and bone structure in bed rest, the question arises how these principle results can best be incorporated for training regimens on board the International space station (ISS). Resistive exercise regimens have shown some efficacy in the past [60], and an improved resistive exercise has been recently made available on board the ISS. The outcome of this and/or future exercise equipment might provide different results. Very recent results from our own laboratory, however, demonstrate that vibration may have beneficial effects in itself (Felsenberg et al., unpublished data), and it is therefore well possible that vibration exercise might be considered for implementation in future space missions.

Results from the DXA measurements are difficult to interpret, mainly due to a considerable measurement variation (Table 3 ). Although no significant effect was observed for the total hip measurements, data in Fig. 7 seem to suggest that the training was not fully effective at the hip, and that the neuromuscular test battery during bed rest might have had a protective effect on the right side. However, the abrupt changes in lumbar spine BMC depicted in the upper panel of Fig. 7 seem to be incompatible with true changes in bone mass and are more likely measurement artifacts, e.g., due to fluid shifts. Therefore, the question arises whether DXA is a viable technique to address bed rest-induced changes of the trunk.

As to the possible osteogenic effects of the knee extension assessment within our neuromuscular test battery, it is evident that it had no effect upon the tibia, except that BMC at the $66 \%$ tibia diaphysis in the Ctrl group seemed to respond slightly differently to bed rest (Fig. 2), which, however, was not statistically significant. However, there is a genuine possibility that the test battery affected bone losses at the hip (see Fig. 7). Unfortunately, these effects did not achieve statistical significance, probably due to measurement variation of the DXA scans. On the other hand, it should be noted that no side difference was found for muscle CSA in the calf and in the thigh.

Finally, it could be argued that the recovery period was not controlled. However, controlling 20 participants for over a year would constitute a huge undertaking. Moreover, it would probably be unresourceful to do so, given that recovery was generally complete after 12 months even without control or intervention.

\section{Conflict of interest statement}

Joern Rittweger and Dieter Felsenberg are acting as a consultant to the European Space Agency and Novotec Medical for exploitation of this study's results.

Dick Stegeman is a member of the Facility Science Team of the European Physiology Module (EPM) in the ISS Columbus space laboratory.

Harald Schubert and Hans Schiessl are directors of Novotec Medical and Stratec Medizintechnik.

All other authors have no conflict of interest.

\section{Conclusion}

In summary, this study has shown that the combination of sidealternating whole body vibration, resistive exercise, and rest-inserted explosive squats can effectively safeguard musculoskeletal of the distal tibia integrity during bed rest. The results of this study give further evidence to the idea that musculoskeletal forces are essential to the adaptation of bone strength.

\section{Acknowledgments}

We wish to express our gratitude to the study participants. Their selfless contribution was outstanding. Also, thanks to staff on ward 18 and in the Department of Radiology of the Charité-Campus Benjamin Franklin and the co-workers of the Centre for Muscle and Bone Research. Henning Soll and Bernd Johannes from the Institute Aerospace Medicine (DLR in Hamburg) were a delightful support in the recruitment process.

\section{References}

[1] Hancock DA, Reed GW, Atkinson PJ, Cook JB, Smith PH. Bone and soft tissue changes in paraplegic patients. Paraplegia 1979;17:267.

[2] Eser P, Frotzler A, Zehnder Y, Knecht H, Denoth J, Schiessl H. Relationship between the duration of paralysis and bone structure: a pQCT study of spinal cord injured individuals. Bone 2004:34:869-80.

[3] Jorgensen L, Crabtree NJ, Reeve J, Jacobsen BK. Ambulatory level and asymmetrical weight bearing after stroke affects bone loss in the upper and lower part of the femoral neck differently: bone adaptation after decreased mechanical loading. Bone 2000;27:701-7. 
[4] Donaldson DL, Hulley SB, Vogel JM, Hattner RS, Bayers JH, McMillan DE. Effect of prolonged bed rest on bone mineral. Metabolism 1970;19:1071.

[5] Berg HE, Larsson L, Tesch PA. Lower limb skeletal muscle function after $6 \mathrm{wk}$ bed rest. J Appl Physiol 1997;82:188.

[6] Convertino VA, Doerr DF, Stein SL. Changes in size and compliance of the calf after 30 days of simulated microgravity. J Appl Physiol 1989;66:1509.

[7] Lueken SA, Arnaud SB, Taylor AK, Baylink DJ. Changes in markers of bone formation and resorption in a bed rest model of weightlessness. J Bone Miner Res 1993;8:1433.

[8] Grigoriev AI, Morukov BV, Oganov VS, Rakhmanov AS, Buravkova LB. Effect of exercise and bisphosphonate on mineral balance and bone density during 360 day antiorthostatic hypokinesia. J Bone Miner Res 1992;7(Suppl 2):S449.

[9] Convertino VA. Neuromuscular aspects in development of exercise countermeasures. Physiologist 1991;34:S125.

[10] Vico L, Chappard D, Alexandre C, Palle S, Minaire P, Riffat G, Morukov B, Rakhmanov S. Effects of a 120 day period of bed-rest on bone mass and bone cell activities in man: attempts at countermeasure. Bone Miner 1987;2:383-94.

[11] Ferrando AA, Tipton KD, Bamman MM, Wolfe RR. Resistance exercise maintains skeletal muscle protein synthesis during bed rest. J Appl Physiol 1997;82: 807.

[12] Koryak Y. Effect of 120 days of bed-rest with and without countermeasures on the mechanical properties of the triceps surae muscle in young women. Eur J Appl Physiol Occup Physiol 1998;78:128.

[13] Alkner BA, Tesch PA. Knee extensor and plantar flexor muscle size and function in response to $90 \mathrm{~d}$ bed rest with or without resistance exercise. Eur J Appl Physiol 2004;93:294.

[14] Alkner BA, Tesch PA. Efficacy of a gravity-independent resistance exercise device as a countermeasure to muscle atrophy during $29 \mathrm{~d}$ bed rest. Acta Physiol Scand 2004; $181: 345$

[15] Watanabe Y, Ohshima H, Mizuno K, Sekiguchi C, Fukunaga M, Kohri K, et al. Intravenous pamidronate prevents femoral bone loss and renal stone formation during 90-day bed rest. J Bone Miner Res 2004;19:1771.

[16] Rittweger J, Frost HM, Schiessl H, Ohshima H, Alkner B, Tesch P, et al. Muscle atrophy and bone loss after 90 days of bed rest and the effects of flywheel resistive exercise and pamidronate: results from the LTBR study. Bone 2005;36: 1019-29.

[17] Shackelford LC, LeBlanc AD, Driscoll TB, Evans HJ, Rianon NJ, Smith SM, et al. Resistance exercise as a countermeasure to disuse-induced bone loss. J Appl Physiol 2004;97:119.

[18] Braun MJ, Meta MD, Schneider P, Reiners C. Clinical evaluation of a high-resolution new peripheral quantitative computerized tomography (pQCT) scanner for the bone densitometry at the lower limbs. Phys Med Biol 1998;43:2279.

[19] Ferretti JL, Capozza RF, Zanchetta JR. Mechanical validation of a tomographic (pQCT) index for noninvasive estimation of rat femur bending strength. Bone 1996;18:97.

[20] Rubin CT, Lanyon LE. Kappa Delta Award paper. Osteoregulatory nature of mechanical stimuli: function as a determinant for adaptive remodeling in bone. J Orthop Res 1987;5:300-10.

[21] Frost HM. Bone "mass" and the "mechanostat": a proposal. Anat Rec 1987;219: $1-9$.

[22] Özkaya N, Nordin M. Fundamentals of biomechanics. New York: Springer; 1998.

[23] Rittweger J. Physiological targets of artificial gravity: adaptive processes in bone. In: Clement G, Bukley A, editors. Artificial Gravity. Berlin: Springer; 2007. p. 191-231.

[24] Rubin C, Recker R, Cullen D, Ryaby J, McCabe J, McLeod K. Prevention of postmenopausal bone loss by a low-magnitude, high-frequency mechanical stimuli: a clinical trial assessing compliance, efficacy, and safety. J Bone Miner Res 2004;19:343.

[25] Gusi N, Raimundo A, Leal A. Low-frequency vibratory exercise reduces the risk of bone fracture more than walking: a randomized controlled trial. BMC Musculoskelet Disord 2006;7:92.

[26] Rittweger J, Winwood K, Seynnes O, de Boer M, Wilks D, Lea R, et al. Bone loss from the human distal tibia epiphysis during 24 days of unilateral limb suspension. J Physiol 2006;577:331-7.

[27] Rittweger J, Felsenberg D. Bed-rest induced bone loss continues after reambulation in humans. Human Physiology Meeting. King's College London: Proceedings of the Physiological Society; 2004. p. C43.

[28] Rittweger J. Simunic B, Bilancio G, Gaspare De Santo N, Cirillo M, Biolo G, et al. Bone loss in the lower leg during 35 days of bed rest is predominantly from the cortical compartment. Bone 2009;44:612-8.

[29] Rittweger J, Felsenberg D. Recovery of muscle atrophy and bone loss from 90 days bed rest: results from a one-year follow-up. Bone 2009;44:214-24.

[30] Rittweger J, Belavy D, Hunek P, Gast U, Boerst H, Feilcke B, et al. Highly demanding resistive exercise program is tolerated during 56 days of strict bed rest. Int J Sports Med 2006;27:553-9.

[31] Armbrecht G, Belavy DL, Gast U, Bongrazio M, Touby F, Beller G, et al. Resistive vibration exercise attenuates bone and muscle atrophy in 56-days of bed-rest: whole body DXA and biochemical markers of bone metabolism. Osteoporos Int 2009 PMID: 19536451.

[32] Harris JA, Benedict FG. A biometric study of basal metabolism in man. Washington, D.C.: Carnegie Institute of Washington; 1919

[33] Abercromby AF, Amonette WE, Layne CS, McFarlin BK, Hinman MR, Paloski WH. Vibration exposure and biodynamic responses during whole-body vibration training. Med Sci Sports Exerc 2007;39:1794-800.

[34] Srinivasan S, Weimer DA, Agans SC, Bain SD, Gross TS. Low-magnitude mechanical loading becomes osteogenic when rest is inserted between each load cycle. J Bone Miner Res 2002;17:1613.

[35] Rittweger J, Beller G, Ehrig J, Jung C, Koch U, Ramolla J, et al. Bone-muscle strength indices for the human lower leg. Bone 2000;27:319-26.

[36] Rittweger J, Michaelis I, Giehl M, Wüseke P, Felsenberg D. Adjusting for the partial volume effect in cortical bone analyses of pQCT images. Journal of Musculoskeletal Neuron Interactions 2004;4:436.

[37] Mulder ER, Stegeman DF, Gerrits KH, Paalman MI, Rittweger J, Felsenberg D, et al. Strength, size and activation of knee extensors followed during 8 weeks of horizontal bed rest and the influence of a countermeasure. Eur J Appl Physiol 2006;97:706-15.

[38] Blottner D, Salanova M, Puttmann B, Schiffl G, Felsenberg D, Buehring B, et al. Human skeletal muscle structure and function preserved by vibration muscle exercise following 55 days of bed rest. Eur J Appl Physiol 2006;97:261-71.

[39] Berg HE, Tedner B, Tesch PA. Changes in lower limb muscle cross-sectional area and tissue fluid volume after transition from standing to supine. Acta Physiol Scand 1993;148:379-85.

[40] Reeves ND, Maganaris CN, Ferretti G, Narici MV. Influence of 90-day simulated microgravity on human tendon mechanical properties and the effect of resistive countermeasures. J Appl Physiol 2005;98:2278-86.

[41] Schiessl H, Frost HM, Jee WS. Estrogen and bone-muscle strength and mass relationships. Bone 1998;22:1-6.

[42] Rauch F, Schoenau E. The developing bone: slave or master of its cells and molecules? PediatrRes 2001;50:309.

[43] Capozza RF, Cointry GR, Cure-Ramirez P, Ferretti JL, Cure-Cure C. A DXA study of muscle-bone relationships in the whole body and limbs of 2512 normal men and pre- and post-menopausal women. Bone 2004;35:283-95.

[44] Nikander R, Sievanen H, Heinonen A, Kannus P. Femoral neck structure in adult female athletes subjected to different loading modalities. J Bone Miner Res 2005;20:520-8.

[45] Frost HM. Skeletal structural adaptations to mechanical usage (SATMU). 2. Redefining Wolff's law: the remodeling problem. Anat Rec 1990;226:414.

[46] Frost HM. Skeletal structural adaptations to mechanical usage (SATMU). 1. Redefining Wolff's law: the bone modeling problem. Anat Rec 1990;226:403.

[47] Huiskes R, Ruimerman R, van Lenthe GH, Janssen JD. Effects of mechanical forces on maintenance and adaptation of form in trabecular bone. Nature 2000;405:704.

[48] Frost HM. Presence of microscopic cracks 'in vivo' in bone. Henry Ford Hospital Medical Bulletin 1960;8:25.

[49] Burr DB, Martin RB, Schaffler MB, Radin EL. Bone remodeling in response to in vivo fatigue microdamage. J Biomech 1985;18:189-200.

[50] Mori S, Burr DB. Increased intracortical remodeling following fatigue damage. Bone 1993;14:103-9.

[51] Ott SM. Theoretical and methodological approach. In: Bilezikian JP, Raisz LG, Rodan GA, editors. Principles of bone biology; 1996. p. 231-41. San Diego.

[52] Parfitt AM, Misconceptions V. Activation of osteoclasts is the first step in the bone remodeling cycle. Bone 2006;39:1170-2.

[53] Uebelhart D, Bernard J, Hartmann DJ, Moro L, Roth M, Uebelhart B, et al. Modifications of bone and connective tissue after orthostatic bedrest. Osteoporos Int 2000;11:59-67.

[54] Smith SM, Zwart SR, Heer MA, Baecker N, Evans HJ, Feiveson A, et al. Effects of artificial gravity during bed rest on bone metabolism in humans. J Appl Physiol 2008.

[55] Lang T, LeBlanc A, Evans H, Lu Y, Genant H, Yu A. Cortical and trabecular bone mineral loss from the spine and hip in long-duration spaceflight. J Bone Miner Res 2004;19:1006-12.

[56] Parfitt AM. Misconceptions (2): turnover is always higher in cancellous than in cortical bone. Bone 2002;30:807-9.

[57] Bruyere O, Dardenne C, Lejeune E, Zegels B, Pahaut A, Richy F, et al. Subchondral tibial bone mineral density predicts future joint space narrowing at the medial femoro-tibial compartment in patients with knee osteoarthritis. Bone 2003;32: 541-5.

[58] Hagino H, Raab DM, Kimmel DB, Akhter MP, Recker RR. Effect of ovariectomy on bone response to in vivo external loading. J Bone Miner Res 1993;8:347-57.

[59] Schriefer JL, Warden SJ, Saxon LK, Robling AG, Turner CH. Cellular accommodation and the response of bone to mechanical loading. J Biomech 2005;38:1838-45.

[60] LeBlanc A, Schneider V, Shackelford L, West S, Oganov V, Bakulin A, Voronin L. Bone mineral and lean tissue loss after long duration space flight. J Musculoskelet Neuronal Interact 2000;1:157-60. 